\title{
Augmenting Austrian flood management practices through geospatial predictive analytics: a study in Carinthia
}

\author{
S. M. Ward ${ }^{1}$ and G. Paulus ${ }^{2}$ \\ ${ }^{1}$ Department of Geography and Anthropology, Louisiana State University, Baton Rouge, Louisiana, USA \\ ${ }^{2}$ Carinthia University of Applied Sciences, School of GeoInformation, Villach, Austria \\ Correspondence to: S. M. Ward (steven.matthew.ward@gmail.com) and G. Paulus (g.paulus@ fh-kaernten.at) \\ Received: 3 October 2012 - Published in Nat. Hazards Earth Syst. Sci. Discuss.: - \\ Revised: 15 February 2013 - Accepted: 20 February 2013 - Published: 11 June 2013
}

\begin{abstract}
The Danube River basin has long been the location of significant flooding problems across central Europe. The last decade has seen a sharp increase in the frequency, duration and intensity of these flood events, unveiling a dire need for enhanced flood management policy and tools in the region. Located in the southern portion of Austria, the state of Carinthia has experienced a significant volume of intense flood impacts over the last decade. Although the Austrian government has acknowledged these issues, their remedial actions have been primarily structural to date. Continued focus on controlling the natural environment through infrastructure while disregarding the need to consider alternative forms of assessing flood exposure will only act as a provisional solution to this inescapable risk. In an attempt to remedy this flaw, this paper highlights the application of geospatial predictive analytics and spatial recovery index as a proxy for community resilience, as well as the cultural challenges associated with the application of foreign models within an Austrian environment.
\end{abstract}

\section{Introduction}

While flooding has long signified one of the most ubiquitous hazard risks throughout Austria, one can argue that the catastrophic flood event in August of 2002 characterizes a seminal moment in flood risk management for the central European nation (European Commission, 2002). The last comparable event to impact this Alpine region occurred in 1899, far surpassing the memory of even its eldest citizens. Without this a posteriori knowledge, it is difficult to imagine flood mitigation being at the forefront of modern Austrian politi- cal agendas. On the surface this statement appears to be an appropriate depiction of the reason behind the devastation in 2002, but a closer look at flood history and flood management in Austria reveals a different story. Dating back to as early as 1954, the Austrian portions of the Lower Danube River basin have been subjected to intense flood events resulting in significant economic damages and loss of life (Blöschl et al., 2012; Arellano et al., 2007). Although none of these events have equaled the 2002 flood, their frequency and intensity have steadily increased, with the first decade of the millennium realizing the most concentrated period of flooding in modern history (Frei et al., 2006; Caspary, 2004). Coincident with the steady rise in flood events throughout the country since the mid-twentieth century, has been a maturation of flood mitigation strategy (Arellano et al., 2007). When considering the fact that Austrian authorities have frequently enhanced flood mitigation efforts over the last $60 \mathrm{yr}$, it is reasonable to question why flooding since the 2002 event has continued to result in such negative impacts throughout the country.

In order to shed light upon this inquiry, the authors have expanded upon flood recovery modelling research initiated in 2009 in the province of Carinthia. Utilizing a spatial recovery index as a proxy for flood resilience in the region, the 2009 study sought to define local flood risk in a context different from the typical engineering based analyses (Ward et al., 2009). The results of this analysis relied upon the application of a recently developed geospatially based model for identifying flood recovery potential. With the application of this model at the core, the intent of the 2009 study was to do the following: 
1. Determine if a geospatially based model developed for an urban area in the United States could be applied to other regions throughout the world.

2. Identify what factors might limit the effectiveness of model execution and value of results.

3. Provide a tool by which planners in the Carinthia region could assess vulnerability to flooding.

While reviewing literature and exploring the results of this analysis, the authors were able to not only answer the aforementioned questions, but also identify a number of subtleties underlying the subject of flood risk within the study region in Lower Austria. More revealing than the spatial distribution of recovery potential was the lack of research and information focused on the socio-cultural aspects of flooding. When considered in conjunction with the structural and engineering focus of the current literature on flooding in the region, it becomes clear that an alternative approach to assessing flood risk is necessary. It is speculated that many flooding problems in Austria stem from anthropogenic alterations to rivers and streams (Arellano et al., 2007). Overmanaging these features has led to a false sense of security, stimulated development in hazard zones, and exaggerated the intersection between vulnerable populations and the physical elements which put them at risk. Continuing to rely on flood mitigation strategies based primarily on the engineering and physical factors driving risk may be inadvertently increasing public apathy towards flooding. Furthermore, it is important that officials charged with flood control begin to adopt a more investigative approach to assessing risk.

\subsection{Flood history and study region}

Central Europe has long been at significant risk from floodrelated hazards, especially those areas lying within the Danube Basin (Zischg et al., 2011). Extended periods of rain and flash flood events associated with the tributaries of the Danube have been characterized as the most important hazard impacting Austrian communities; yet, the hazardscape of many portions of the country remain largely misunderstood (Blöschl et al., 2012; Gaume et al., 2009). Exasperating the impact of this risk is the fact that over $70 \%$ of the Austrian landscape is covered by mountainous terrain (Keiler et al., 2010; Staffler et al., 2008). This steep topography limits developable land and in turn has led to unsustainable development patterns and dense population distribution (EmbletonHamann, 1997; Url and Sinabell, 2008). When one considers this in conjunction with the fact that over 93 people per square kilometer live within the Austrian territory drained by the Danube, the grave nature of this risk is quite humbling (Schönerklee, 2008). An analysis of the 2002 flood event reinforced this threat, suggesting that over $40 \%$ of the flooded areas were heavily developed based on legal land use planning ordinances (Paulus et al., 2004). An Embleton-
Hamann (1997) study also advises that 9-12\% of structures in Austria are considered to be at extreme risk to floods.

To state that the 2002 flood event did not result in a renewed interest in limiting the impacts of hazards would be misleading. Austrian authorities have taken significant steps to understand the driving factors behind floods, to quantify their risk, and to communicate this risk to planners and citizens. Furthermore, the need for increasingly sophisticated understanding of flood risks has not gone unnoticed by the European Union (EU) (Paulus et al., 2004). The EU Flood Directive, developed in 2006, has called for a reduction in flood-related risks to health, property and infrastructure (Paulus et al., 2004). Leading up to the establishment of this directive, the nations impacted by the 2002 event gathered at a workshop hosted in Vienna. Experts in numerous floodrelated fields worked to develop a series of recommendations related to flood risk reduction strategies (Nachtnebel, 2007). The fatal flaw in this workshop, as pointed out by Nachtnebel (2007), was the fact that the shortcomings to flood risk management identified in Vienna were no different than those identified following floods a half-century prior. To this end, Nachtnebel (2007) has suggested that insufficient implementation and coordination are the primary limiting factors to improved flood risk management in Central Europe.

This lack of follow through on flood mitigation planning is not as pervasive as Nachtnebel (2007) might suggest. Varying levels of action can be seen across the Central European countries represented at the 2003 Vienna workshop, and in turn several regions of Austria have seen a proactive movement towards improved flood management. Of particular interest is the federal state of Carinthia. Following the 2002 floods, the Hydrologic Department of Carinthia developed a database-driven software system to house flood and water-related data for retrieval and analysis. The system offers users the capability to conduct flood impact assessments and a platform for information exchange between experts and scientists in the region. Coincident with the development of this application was the initiation of the Natural Hazards in Carinthia project. This project incorporated many of the EU Flood Directive requirements and is widely considered to be one of the first interdisciplinary studies focused on hazards and risk management in the region (Paulus et al., 2004). This integrated approach to risk management in Carinthia is consistent with a trend in Austria which has seen the management of natural hazards transition from dealing with individual hazards to an all-hazards perspective (Zischg, 2011). At a national level, the Hochwasserrisikozonierung Austria (HORA) was launched in late 2002 by the Federal Ministry of Agriculture, Forestry, Environment, and Water Management (BMLFUW, 2006). By 2006, the program released its first maps depicting nationwide flood risk at the 30,100, and $300 \mathrm{yr}$ return periods via an online version of HORA (eHORA) (Zischg, 2011). Prior to the eHORA release, flood damages and management processes were handled differently by each federal province (Faber, 2006). The eHORA 
platform depicts flood zones in much the same way as the Digital Flood Insurance Rate Maps prepared by the Federal Emergency Management Agency in the United States. As informative as the eHORA platform proved to be, the analysis used to generate its data was limited to a steady-state model which does not consider discharge, impacted structures, impacted population, or any other details. For this reason, the map's usefulness is restricted to basic development decisions.

Despite the efforts highlighted in the previous paragraph, recent studies have described the administrative areas within Lower Austria as having the highest level of flood risk in the country (Embleton-Hamann, 1997). Couple this with the significant risk of torrent hazards and Carinthia represents a particularly vulnerable region in Lower Austria. Carinthia offers a unique blend of both mountainous terrain and relatively flat valleys populated with well-established urban, suburban, and rural communities intersected by numerous rivers and streams (Kosaret al., 2011). Bearing these characteristics in mind, Carinthia presented itself as an ideal candidate for this study. Based on data availability, the municipalities of Klagenfurt, Ebenthal, Maria Saal, and St. Veit an der Glan were selected for analysis (Fig. 1). These areas were determined to be representative of both the physical and cultural geography of Carinthia, allowing for broader conclusions to be drawn from results of the analysis. The primary rivers dividing the study region are the river Glan and the river Gurk. The confluence of these two features is in the Ebenthal region in the southern portion of the study area.

The analysis and data collection phase of this study was initiated in June of 2009 at the Carinthia University of Applied Sciences (CUAS) to the west of the study region in Villach, Austria. Complementary research on Natural Hazards in Carinthia was being conducted at the university during the same time frame, offering a healthy academic environment for this project. Data for this study was largely provided by KAGIS, Corine Land Cover (CLC) and the government of Carinthia. The initial stages of the work were presented at the 2009 GI-Forum in Salzburg and a companion study was conducted at CUAS in 2010 (Kosar et al., 2011). While research can often be conducted from remote locations, centring it in Carinthia provided invaluable insight into the at-risk geography and communities being studied.

\section{Spatial recovery index: methods and results}

The spatial recovery index (SRI) was initially developed as a rapid means of assessing post disaster recovery based upon the spatial distribution of undamaged critical infrastructure (Ward et al., 2010). An evaluation of the results of the SRI demonstrated variations in the model's fidelity based on the structure of input parameters as well as scale. Further research has demonstrated that the index has potential benefit as a metric for resilience when applied to pre-event condi-

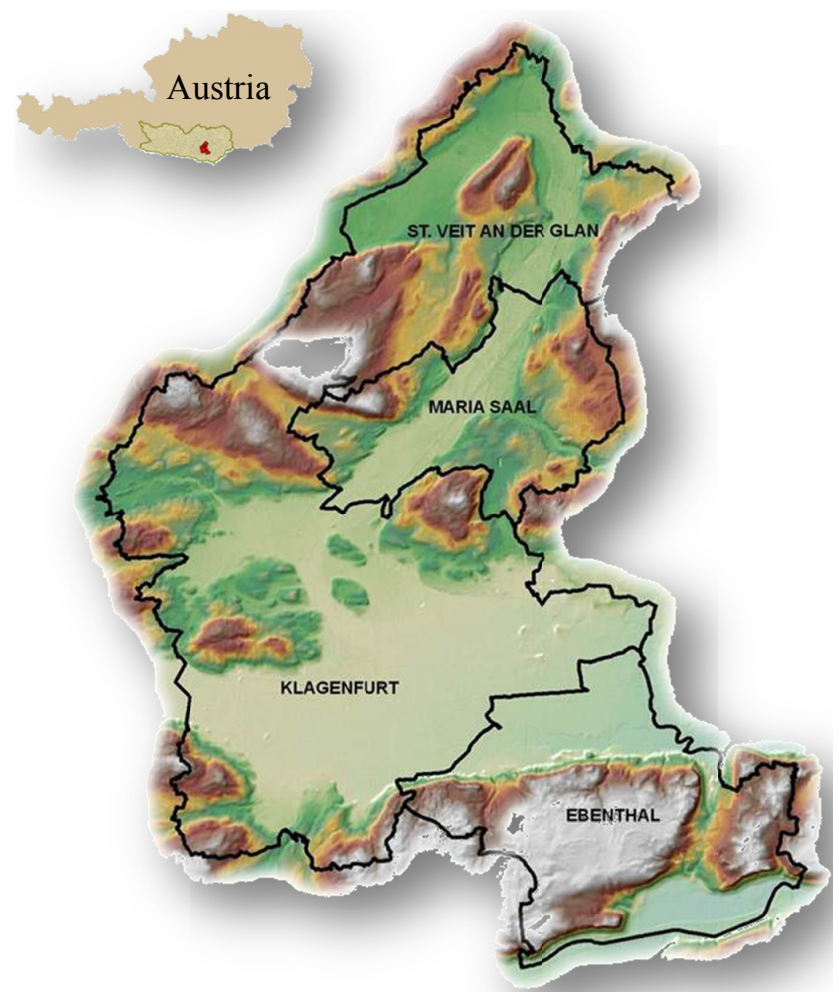

Fig. 1. Study area in Carinthia Austria.

tions (Ward et al., 2010). In consideration of this probable value and the narrow flood management scope identified in the current literature, the SRI was used to assess flood risk in the study region. Offering an alternative measure of flood risk across the community provides the initial shift away from engineering centric flood management strategies called for in recent work (Gaume et al., 2009; Faber, 2006; Ganoulis, 2009). Url and Sinabell (2008) have also called for policy, insurance, and social consideration to drive a new integrated approach to flood management in Austria. The SRI also answers the call of Paulus et al. (2004) and Szabó (2007), who have independently cited the need for an increased application of geospatial technology for hazards and disasters management in the region.

Based upon the results of their prior research, the authors have posited that flood resilience can be measured rapidly in the absence of social or even flood-related data by using the spatial proximity of structures. This can be realized because of the fact that structures are not one dimensional when considered in the recovery context. Buildings and their intended purpose are facilitators of social networks (i.e. schools, churches, community centres, and athletic clubs). For instance, the negative consequences associated with an individual residence impacted by a flood will generally be isolated to a single family. On the other hand, buildings which house critical infrastructure or social capital have the ability to impact a much larger portion of the 
population as multiple families rely on them as part of their social network. The SRI model is based on the notion that buildings which provide services to the entire community have more importance to the resilience of that community than any single family dwelling (Ward et al., 2010). This can be evidenced in the case of a water treatment facility being damaged by a flood, restricting the entire community's access to potable water whether or not the flood impacted the community itself. By identifying the spatial location of structures housing the key components of social networks within a community, one can begin to create a spatial network or sphere of influence that each structure contributes to the public. When combined with the "spheres" of all other components, a surface depicting resilience or recovery potential can be created. This overall range of influence is captured by the SRI and can be run pre-event or even post-event based on damaged facilities. Because all of this analysis is conducted using the geoprocessing capabilities of GIS software, the data can then be analysed to identify characteristics about the distribution of resilience across the study region, or compared to engineering studies to offer decision makers a more comprehensive view of risk.

\subsection{Carinthia case study}

In the case of the Carinthia study, three variants of the SRI were conducted based on varying input parameters, model structure, and scale. The multiple iterations were necessary to understand what modifications were necessary to properly employ the model. The SRI was originally developed to operate in the urban environment of a medium-sized city, and it was suspected that running an unmodified version may produce misleading results. A variety of input variables are divided into recovery indicators (i.e. structures) and vulnerability indicators (i.e. flood zones). The influence of each of these variables on the community is based on distance decay theory and represented using a Euclidean distance conversion to a raster dataset with the same cell size as the elevation DEM. These two categories are then combined in the model using an additive raster calculation to produce a final SRI value. From this output the data can be resampled, divided into administrative units with a zonal analysis, or analysed for patterns and relationships.

\subsection{SRI 2009}

The first model runs were conducted using the exact framework as the original SRI detailed in the 2009 study in New Orleans (Ward et al., 2010). Every available dataset for the study region which was part of the original SRI data structure was clipped and incorporated into the analysis. These datasets included railroads, power lines, churches, schools, healthcare facilities, roads, flood zones, elevation, fire brigades, police stations, gas terminals, rivers, and water stations. The output from this scenario was intriguing as it demonstrated a higher level of resilience and less variance than expected (Fig. 2a). The same trend was present when the model was executed with just the recovery indicators (Fig. 2b). The vulnerability indicators associated with elevation, slope, flood zones and other natural features revealed a normal distribution of vulnerability in relation to rivers in the region when run on their own (Fig. 2c). The symbology in Fig. 2 depicts high recovery potential in green decreasing on a colour gradient from yellow to orange, and finally to red, which is indicative of the least resilient areas of the region.

The lack of variation in the output of this initial SRI analysis suggests a flaw in model inputs or structure. Segregating the components of the model into individual variables shows that the number of buildings included in the recovery indicators far exceeded the total number of variables ever run in the model, artificially enhancing the value of these input variables and homogenizing the model output. This high number of records was symptomatic of the large study area, a higher quality data set and the pre-event status of the scenario. However, the results of this first model run did demonstrate that the necessary data were available to run the model and produce results which had some spatial commonality with the flood zones from eHORA.

\subsection{SRI 2010}

With the intention of improving upon these results, Kosar et al. (2010) ran a second iteration of the SRI in the same study region. It was the intention of this analysis to modify the construct of the model to account for the large study region and inordinate amount of input data. The research in the 2010 study determined that many of the recovery indicators classified in the original study under specific categories were redundant and incorrect (Kosar et al., 2011). Being more familiar with the local datasets and colloquialisms of their attribution, Kosar et al. (2010) were able to build a recovery data model more representative of real world conditions. This improved version of the model was driven by only the most important variables gleaned from the much larger regional datasets, dividing the data into five variable categories: care institutions, cultural resources, infrastructure, economy and municipal buildings. These variables were selected based on those used to assess recovery in the UN Tsunami Recovery project (UN, 2005). The categories used by the UN to assess recovery in the countries affected by the Indian Ocean tsunami were designed to be used from a regional perspective (UN, 2005). This new model structure better represented the structure data available for this study, and removed the duplicative information which was not of importance to the model. In addition, this reiteration of the SRI was conducted at a finer resolution. All of the analysis was conducted using a cell array consisting of $9 \mathrm{~m}$ as oppose to $25 \mathrm{~m}$. This improved resolution provided an increased level of detail in the final output of the model, allowing for more subtle trends to be identified throughout the study region. In addition to the 

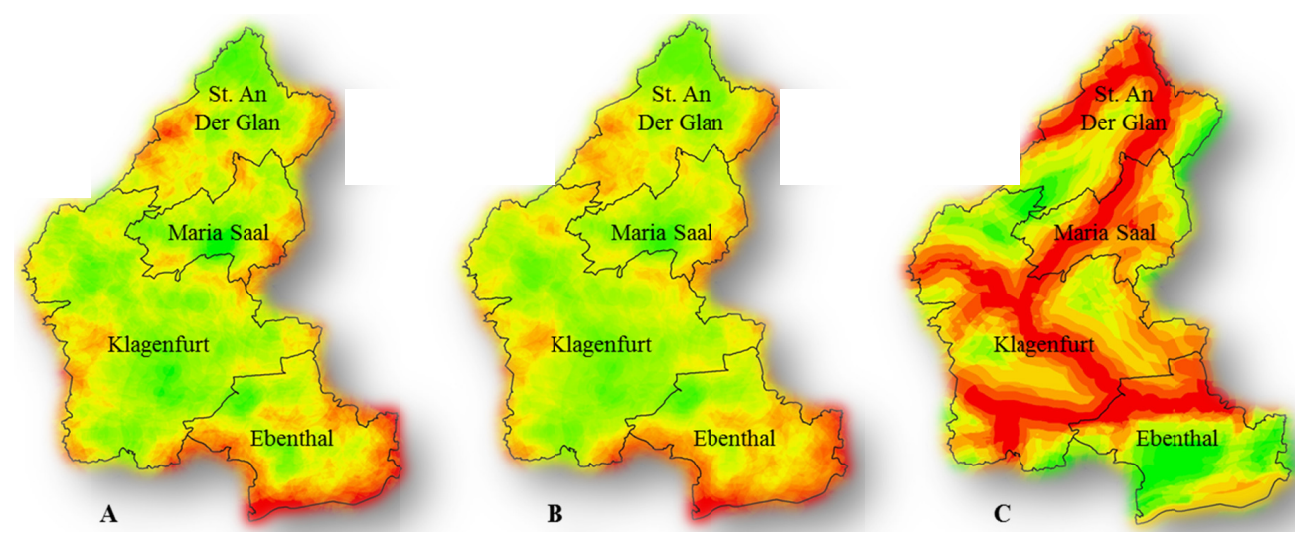

Fig. 2. Three components of 2009 SRI analysis.

modification in cell size for the analysis, the relative weight of recovery indicators and vulnerability indicators were considered. Kosar et al. (2011) speculated that in addition to the aforesaid faults with the recovery data, the vulnerability indicators were also contributing to the limited detail in the model output. To account for this proposed flaw, the vulnerability indicators were weighted forty percent less than the recovery indicators in the final SRI output.

At a cursory glance, the output of the Kosar et al. (2011) SRI analysis produced varying results from the original SRI analysis in 2009. Figure 3 compares the original SRI output to the modified version using the same symbology to represent recovery potential as that used in Fig. 2. When comparing the two assessments, the overall recovery potential for the study region is fairly consistent with the exception of a few areas. The rural corridor between St. Veit An Der Glan and Maria Saal, the areas of Ebenthal to the southeast of Klagenfurt and the region to the northwest of Klagenfurt all have a reduced capacity for recovery based on Kosar's SRI methodology. Review of the individual data components in these regions unveils similarities in their physical geography which may be leading to the consistency in their low level of recovery potential (Kosar et al., 2011). Kosar also suggests that the large number of structures supporting social networks within the cities has a high level of influence on the high SRI scores in these areas. While a distinct change in output exists between these two models, it is unclear based on the work by Kosar et al. (2011) what is driving this dynamic. By altering the structure, input variables, weighting scheme, and grid cell size in a single model run, it is impossible to determine if a single modification or a combination of adjustments have led to the variance in model output. The 2010 analysis was also restricted by the fact that it did not analyse the data using administrative units smaller than the municipality. While areas such as Klagenfurt appear to be largely immune when viewed at the municipal or regional scale, analysing the results from these areas at varying administrative units (i.e. postal codes, neighbourhoods, land use, etc.) may tell a different story.
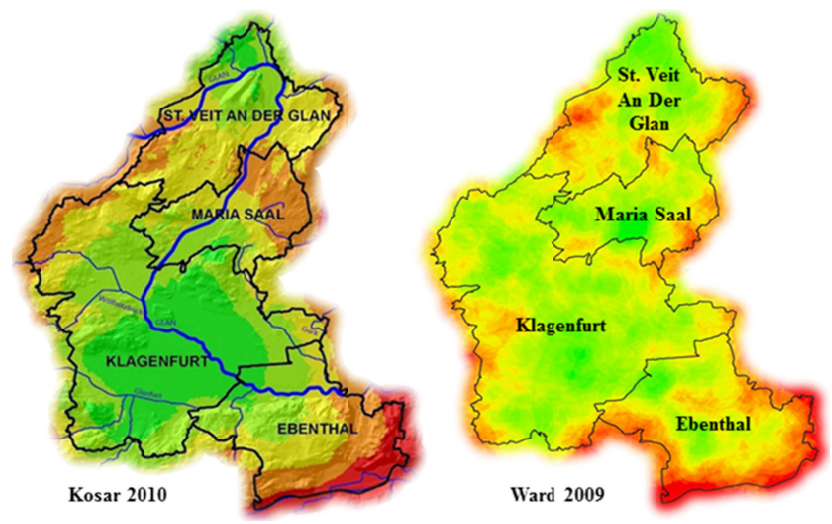

Fig. 3. 2010 Kosar SRI compared to 2009 Ward SRI.

Kosar et al. (2011) attempted to address this issue by executing the model for Maria Saal by itself, demonstrating that varying the scale has significant influence on the model output. Unfortunately, this single model run at the municipal scale is inadequate when attempting to draw conclusions on component influence and city-wide recovery potential. Although these limitations may restrict the model from being an effective decision support tool, the revised methodology employed in the 2010 study did produce results which were more easily interpreted and more consistent with the distribution of population across the landscape. This improvement was further confirmed when the output was compared to the flood risk zones depicted on eHORA. While the extent of the eHORA delineated risk zones is not as expansive as the high risk areas identified by the SRI, the general trend of risk transitioning from low to high potential for recovery from Klagenfurt throughout the rest of the study area is represented.

\subsection{SRI 2011}

In late 2011 the topic of recovery in the same region of Carinthia was revisited once more in an attempt to further refine the SRI methodology. Prior to this analysis, Zischg et 
Table 1. Recovery and vulnerability elements included in 2012 enhanced Austrian SRI.

\begin{tabular}{llll}
\hline $\begin{array}{l}\text { Recovery } \\
\text { (Buildings) }\end{array}$ & $\begin{array}{l}\text { Recovery } \\
\text { (Infrastructure) }\end{array}$ & $\begin{array}{l}\text { Vulnerability } \\
\text { (Physical) }\end{array}$ & $\begin{array}{l}\text { Vulnerability } \\
\text { (Hazards) }\end{array}$ \\
\hline Schools & Roads & Elevation & Hydrology \\
Hospitals & Bridges & Slope & Flood Zones \\
Fire Stations & Railways & & $\begin{array}{l}\text { Flood Control } \\
\text { Structures }\end{array}$ \\
Police & Power Lines & Major Roads \\
Industrial & Gas Lines & \\
& Water Stations & \\
& Electric Stations & & \\
& Industrial Areas & & \\
\hline
\end{tabular}

al. (2011) approached the assessment of risk to natural hazards in Carinthia as a function of climate change. This European study took a very similar approach to the original SRI analysis which considered structures as key elements of vulnerability. Just as Ward et al. (2010) postulated in the New Orleans study, Zischg et al. (2011) identified a list of at-risk elements exposed to hazards. These elements were largely structural in nature and grouped into three categories: buildings (e.g. buildings, schools, and domiciles), infrastructure (e.g. roads, power lines, bridges, gas lines, and railways), and agriculture (e.g. farmland, grassland, and forest). These categories were derived from the European Water Framework Directive and the guidelines for cost-benefit analyses in hydraulic engineering (BMLFUW, 2006, 2008). These categories were reviewed by a team of local administrators in Carinthia to adjust for native conditions. Prior to the Zischg et al. (2011) study, the SRI had been used in Austria with little variation in the methodology or recovery features included in the model. With the intent to modify the index to be more reflective of Austrian ideology, the SRI analysis was conducted in 2012 using these new at-risk elements to replace the original recovery indicator components.

When considering these categories in the context of the SRI methodology, there are two very interesting variances. The first is the heavy focus on domiciles (single-family and multi-family), while the second is the lack of any cultural or commercial facilities. No churches, banks, pharmacies, grocery stores or elder care facilities were included in the atrisk elements classification used in the Zischg et al. (2011) study, indicating a possible variation in Austrian risk perception when compared to that identified in New Orleans. While Zischg et al. (2011) progress to an increasingly complex assessment and estimation of impacted population based on the conflation of various datasets focused on these at-risk elements, the SRI adopted a less intricate approach. It was important for the SRI analysis on these new classes to stay true to its original intent and only consider these elements from a spatial perspective. The final SRI run used the Austrian atrisk elements detailed in Table 1.
This input data represented a significant reduction in variables used to calculate the SRI when compared to the aforementioned versions of the analysis. This decrease in input variables was welcomed as the overwhelming volume of data used in the 2009 study was suspected of reducing the quality of the model output. The data layers were each converted to a raster format using the geoprocessing procedures outlined in the 2009 SRI study in New Orleans (Ward et al., 2010). These raster files represented each at-risk element's potential level of influence on recovery based on Euclidean distance. The level of influence on recovery for each element was inversely related to the distance between structures. These rasters were summed using a raster calculation to create a single layer representing recovery potential for the entire study region. The output of this SRI analysis is compared to the 2009 and 2010 indices in Fig. 4.

Visual inspection of the 2012 SRI results illustrates a balance between the data-rich 2009 study and the heavily manipulated 2010 analysis. The primary distribution of recovery potential across the study area is very similar using all three methods, but further analysis of the 2012 data revealed significant patterns which were not present in the 2009 and 2010 studies. Using a global spatial autocorrelation (Moran's I) tool in the spatial statistics extension in ArcGIS, the results of the 2012 study were analysed. The Moran's I analysis demonstrated significant clustering of recovery potential throughout the study region (Fig. 5) with a Moran's I index value of 0.85 and $p$ value of 0.00187 , both of which designate clustering at a significance interval of 0.01 . Having not seen a significant level of clustering in the output of the 2009 and 2010 iterations of SRI, it was important to gain an understanding of the nature of the general trend identified in the 2012 study.

Significant areas of high and low clustering or "hot/cold spots" were examined using a local Getis-Ord Gi* analysis. This statistical method assigned a $z$ score and $p$ value to each cell in the final output raster and identified significant areas of high and low clustering of recovery potential. Areas with a high $z$ score and low $p$ value represent hot spots (red) where high recovery values are clustered, while areas with low negative $z$ scores and small $p$ values indicate cold spots (blue) where low recovery values are clustered (Fig. 6). All other cells in the output raster have $z$ scores near zero which indicate no apparent clustering of recovery values.

Reviewing both the global and local statistics reveals the highest clustering of recovery potential in the urban areas of Klagenfurt, Maria Saal, and St. Veit An Der Glan. These urban centres are obvious choices for high recovery potential due to their density of at-risk elements and structures. Of greater interest to emergency managers in the region may be the smaller clusters of high recovery potential northwest and southwest of Klagenfurt as well as the clusters of low recovery potential in Ebenthal and to the east and west of St. Veit An Der Glan. The lack of at-risk elements in these regions provides limited options within the built environment 

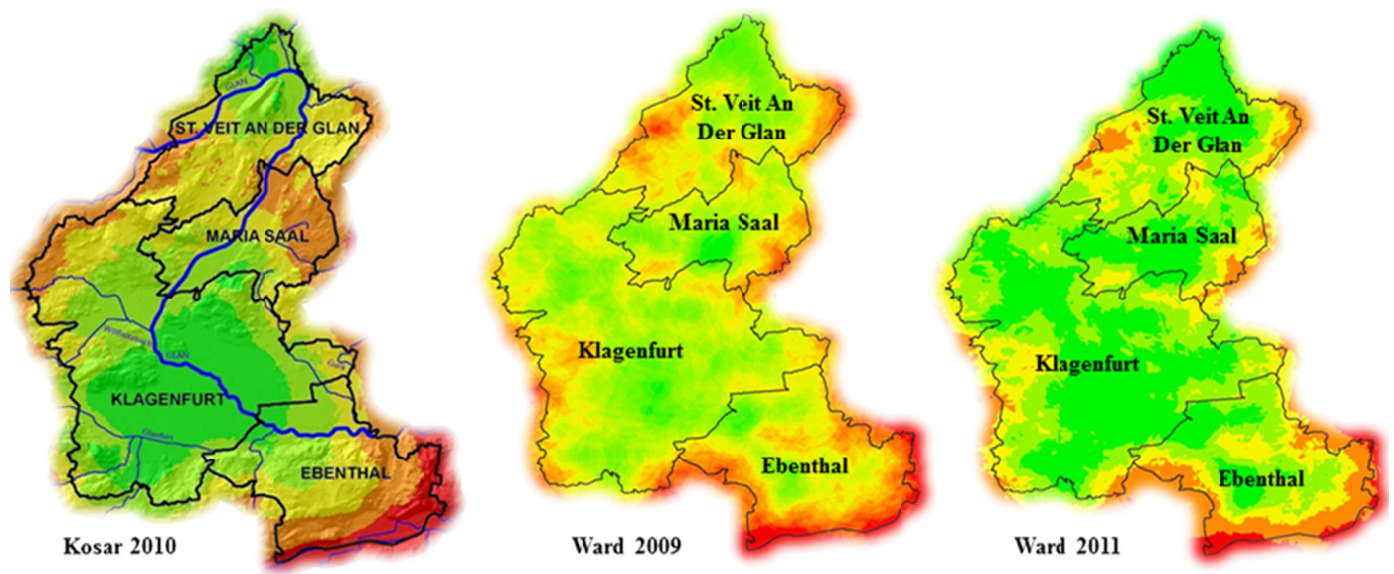

Fig. 4. Comparison of 2009, 2010, and 2011 SRI results.
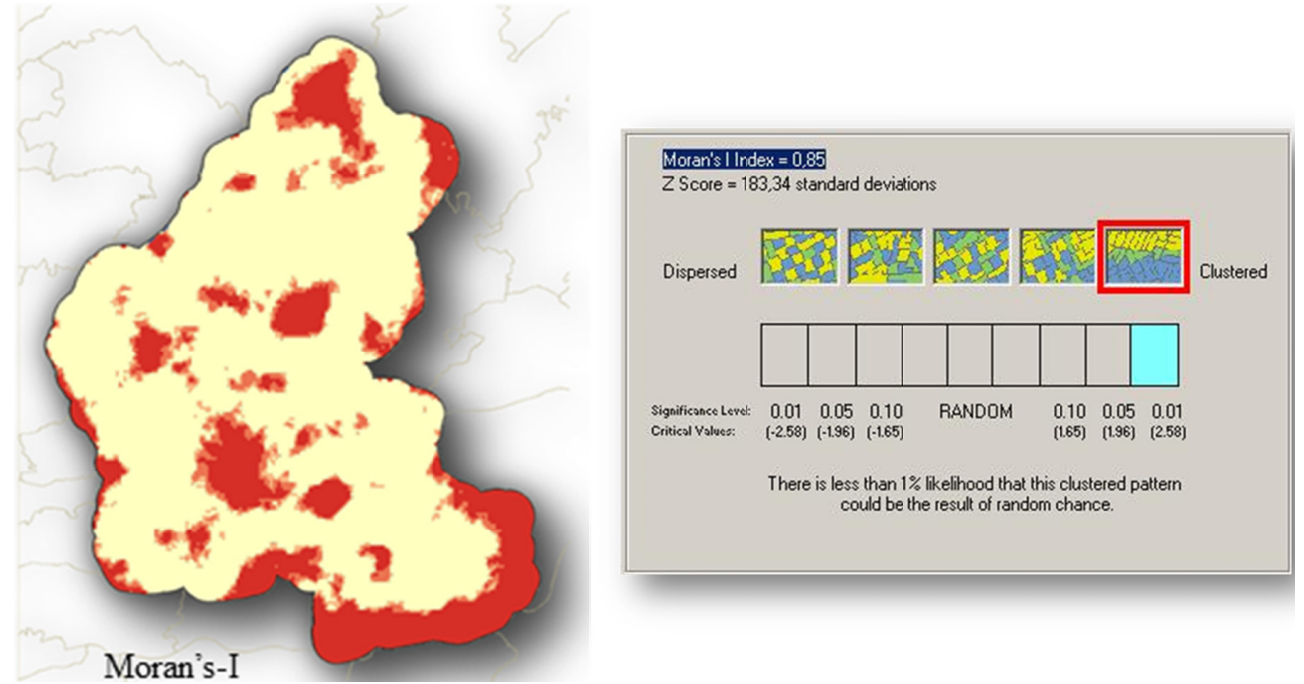

Fig. 5. Global spatial autocorrelation - Moran's I results.
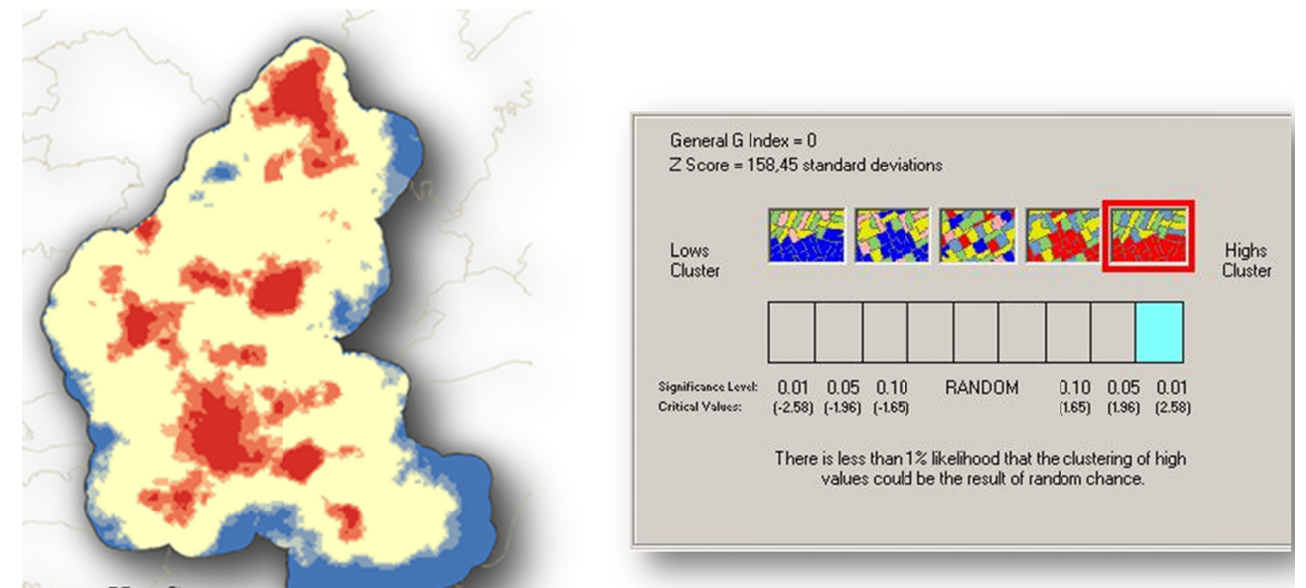

Hot Spot:

Getis Ord Gi*

Fig. 6. Local spatial autocorrelation - Hot spot analysis (Getis-Ord Gi*). 
for recovery to anchor to. These clusters represent latent areas of vulnerability which may exacerbate the management and mitigation of floods in the region. To put these findings into perspective, one must imagine the entire state of Carinthia or country of Austria riddled with these dormant pockets of low recovery potential, creating a network of vulnerability to floods which cannot be ameliorated by means of structural flood control alone.

\section{Risk perception in Austria}

Though the results of this third iteration of the SRI proved to be far more promising than the early efforts by Ward et al. (2010) and Kosar et al. (2011), the fact that the benefit came at the expense of the cultural component of recovery indicators was stimulating. This was exaggerated further when considering the importance of churches and education facilities in the New Orleans study, leading to the conclusion that the application of the SRI in Austria may be suffering from risk perception issues. Without a thorough understanding of risk perception values within Austrian culture, and little documentation of local recovery from large flood events, appropriate input variables are difficult to identify. Including too many variables may dilute the results of the study (see Ward et al., 2010), while excluding important variables will overgeneralize the results (see Kosar et al., 2011). This indefiniteness of input variables highlighted the underlying cultural context, which is important to consider when assessing risk and vulnerability. Zischg et al. (2011) began to touch on this in the discussion of his analysis by suggesting that disaster management in Austria is experiencing a shift to a more integrated approach. This approach will call for more responsibility to be placed on the individual for damages incurred from flooding, but can only be accomplished with improved communication and comprehensive risk perception (Zischg et al., 2011).

The notion of culturally driven risk perception having influence on the application of the SRI is not implausible when cultural theory is considered. In order to gain a better understanding, Gierlach et al. (2010) investigated this phenomenon with interesting results. They found that risk perception across cultures has little to do with exposure to a disaster and more to do with an optimistic bias or "not in my backyard" mentality generated by social construct (Emerging Health Threats Forum, 2008). The idea that hazards play more of a global risk than a local risk is pervasive across cultures and often results in imprecise valuation of risk, vulnerability, and preparedness (Emerging Health Threats Forum, 2008). In light of this, personal experience and socio-cultural factors will often be superseded by ideologies created by groups within the community (Emerging Health Threats Forum, 2008). For instance, individual members of a congregation at a church may undervalue individual risk based on the fact that as a group they are more resilient. This notion is fur- ther supported by the work of Burton (1972), which points to inflexibility in social and institutional perceptions as a leading cause of repetitive loss to disasters.

In Austria it has been stated that this type of risk perception varies across the country based on expectancy-value theory (Thomas, 1981; Hobfoll, 2001). In other words, what benefit do I gain or lose from taking steps to prepare for a flood event? Answering this question can be problematic for the public official who has to balance highly technical risk and vulnerability assessments with public risk perception requiring practicality and benefit (Renn, 1998; Homan, 2001). In light of this predicament, the application of methods used to assess vulnerability or recovery potential should be applied with cultural values in mind, whether they are a social metric or not. As such, the SRI as a stand-alone quantification of recovery potential will hold little value with the general public. In order to improve perception with assessment tools such as the SRI, the analysis must be conducted from the appropriate cultural perspective and presented in conjunction with additional factors (Fleischhauer et al., 2012). These factors can be referred to as "soft facts" which underscore the "hard facts" or results of technical assessments (Schmidt, 2004). A better understanding of the "soft facts" influencing risk perception in Austria will lead to an improved SRI model based on a refined set of at-risk elements.

As previously stated, current risk and vulnerability assessments in Austria are based primarily on management of river systems and structural control measures (Faber, 2006). This trend is symptomatic of water resources managers who are disconnected from impacted populations. This disconnection in Austria has been highlighted in the European Social Survey (ESS) data over the last decade (European Social Survey, 2011). The ESS is a comprehensive biennial survey conducted across Europe to assess general social sentiment and includes political, social, moral, demographic, health, and well-being variables. Over the course of the last decade, hundreds of survey responses have focused on floods and natural disasters across Europe, with only a single response in this category coming from Austria in 2002 (European Social Survey, 2011). Previously cited literature suggests that the government is spending a significant volume of money on adapting flood management and policy to new norms. With this being said, why is the risk of flooding receiving so little recognition from the Austrian public? The answer is undoubtedly multi-faceted and not attributable to a single cause, but may be highlighted in the same survey. When reviewing all of the Austrian data collected as part of the ESS, the topics of political performance and trust come up on a recurring basis (European Social Survey, 2011). This lack of trust towards government officials is expounded upon by the Austrian Academy of Sciences (Gazsó, 2008), who characterize the Austrian public as one that is slow to adopt change in regards to new technology and policy. This study also suggests that tight political regulations and little tradition of public debates amongst a relatively young population also 
contribute to a passive view towards change, whether that be policy, technology, building standards, etc. (Gazsó, 2008). When formulating risk perception towards natural hazards, this detached mentality to policy change and political communication can have dire consequences, as its fault may only be recognized following a disaster. In order to improve upon risk communication between the government and the public, credibility of risk assessment tools must be established through improved risk communication (Reid, 1999). This will in turn lead to a better understanding of how the public perceives risk, what mechanisms of the social network are at greatest risk, and finally, which structures within the built environment are necessary to sustain these social mechanisms (Fleischhauer, 2012). With this information in hand, the SRI can be applied using empirical recovery indicators which are correlated with public risk perception.

\section{Discussion}

By examining the role of predictive spatial analytics in flood management and mitigation, this study has expanded upon the aforementioned evolution of risk management in Austria. Although the initial phase and scope of the study was to apply the spatial recovery index in Carinthia, the use of this technology also led to a complementary summary of cultural influence on risk perception and recovery potential. The two crucial questions behind this investigation focused on the transferability of an urban index developed in the United States to a regional level in Austria, and the influence of culture on the assessment of potential for community recovery. In short, the answer to these is that the SRI can be utilized to assess recovery potential in Austria, but only with significant consideration given to the cultural setting it is being applied in. With this being said, it must be noted that this assessment was written from an American perspective based on observed data and research in the study region. As such, the information associated with this study does not lend itself to extrapolation across the rest of the state or country, but does offer a practical framework to build from.

Through three iterations of the SRI model, this study was able to identify that the variables input into the model had more influence on its outcome than the model structure, resolution or weighting scheme. The results of the analysis indicate that although the corridor between Maria Saal and Klagenfurt may be one of the most vulnerable to floods in all of Austria, the density of recovery indicators in the Klagenfurt area may be able to offset the impacts of a widespread flood. More isolated and localized flooding in the region may result in problematic recovery for areas in Ebenthal and north of Klagenfurt which do not have the combination of recovery elements to facilitate social stability. The analysis could benefit from detailed post-flood data in the region which would allow for the most influential at-risk elements to be identified. Moving forward, it would also be beneficial to run different components of the SRI at varying scales. Isolating the urban areas and rural areas into separate model runs may begin to offer more detail on the variance explained by each indicator used in the analysis, and it would also help eliminate some of the overwhelming volume of data used in the first iteration of the study. In addition, adapting the land cover class developed by Zischg et al. (2011) to account for agricultural lands versus non-agricultural lands may reveal a nuance in recovery potential undetected in the scenarios used in this study. It should also be stated that floods do not present the only hazards in this Alpine region. Torrents, avalanches and landslides represent a few of the other hazards in this region of Carinthia. Couple any one of these events with a large flood event and predicting recovery becomes considerably more complex.

The nuances in recovery potential across this regional setting represent a critical missing component in current flood management practices in Austria. At present, individual structures are not viewed as enablers of social networks, and as such their function and the people they house are placed in a secondary tier of flood management in Austria. One-dimensional flood management and reduced risk communication have created a culture with a skewed perception of resilience, risk, and vulnerability. In addition, personal responsibility for flood damages are dwindling and an obligation for rapid and thorough recovery has been left largely in the hands of government (Zischg et al., 2011; Fuchs, 2009). Zischg et al. (2011) recognized this in their loss estimation study, and called for new tools to assess the various components of disasters in Austria. In order to be effective, these tools had to be able to identify vulnerable hot spots, distinguish between factors driving vulnerability and risk, and be easily updated with new data and information (Zischg et al., 2011). The results of this study suggest that with limited refinement, the SRI will meet all of these criteria in a simple and adaptable spatial decision support tool. Combining the SRI's prediction of recovery with other non-structural measures of vulnerability could place Carinthia at the forefront of flood management practices in Europe.

The integration of cultural values into non-social metrics in disaster science is not a new idea, but has been relatively dormant in the literature for some time. The recent increase in hazard intensity and frequency across the globe has resulted in a renewed interest in the intersection between these two subjects. This condition was recently illustrated in Austria by Kulmesch (2010), who faced numerous challenges when trying to transition Hazards US (HAZUS) loss estimation models to Austrian communities. In addition, the Federal Emergency Management Agency (FEMA) has only just initiated the RiskMap programme which features the opportunity to combine cultural, social, and non-engineering-based vulnerability assessments with ancillary flood map products (FEMA, 2008). These emerging trends are blurring the lines between risk perception, technologically driven risk assessment, and communication 
in a manner which provides a new perspective for managing flood hazards. This new viewpoint is a necessity for proactive management of hazards as human environments are increasingly overlapping hazardous geographies around the globe. In a community where the most hazardous geographies are already populated and developed, it does no good to "help" people by delineating flood zones on a map. Communities must find ways to retroactively mitigate flood risk by quantifying and defining recovery potential across these zones, better focusing mitigation funds, and enhancing risk awareness and communication.

Edited by: K.-T. Chang

Reviewed by: two anonymous referees

\section{References}

Arellano, A., Vetere, L., de Roo, A., and Nordvik, J.-P.: Reflections on the Challenges of EU Policy-Making with View to Flood Risk Management: Actors, Processes and the Acquis Communautaire, in: Flood Risk Management in Europe, edited by: Begum, S., Stive, M. J. F., and Hall, Jim W., New York, NY: Springer Press, Section V, 2007.

Blöschl, G., Merz, R., Parajka, J., Salinas, J., and Viglione, A.: Floods in Austria, in: Changes in Flood Risk in Europe, edited by: Kundzewicz, Z. W., IAHS Special Publication 10, Wallingford, Oxfordshire, 2012.

BMLFUW: Richtlinien für die Wirtschaftlichkeitsuntersuchung und Priorisierung von Maßnahmender Wildbach- und Lawinenverbauung gemäß $§ 3$ Abs. 2 Z 3 Wasserbautenförderungsgesetz 1985, Teil I: Kosten-Nutzen-Untersuchung (KNU) und standardisierte Nutzenuntersuchung, Teil II: Leitfaden Prioritätenreihung, Wien, 2006 (in German).

BMLFUW: Kosten-Nutzenuntersuchungen im Schutzwasserbau, Richtlinie, Wien, 2008 (in German).

Burton, I.: Cultural and Personality Variables in the Perception of Natural Hazards, in: Environment and the Social Sciences: Perspectives and Applications, Wohlwill, J. F. and Carson, D. H., American Psychological Association, New York, NY, USA, 184195, 1972.

Caspary, H. J.: Zunahme "kritischer" Wetterlagen als Ursache für die Entstehung extremer Hochwasser in Südwestdeutschland, KLIWA-Symposium (Klimaveränderung und Konsequenzen für die Wasserwirtschaft-Fachvorträge) in Wurzburg, 3 und 4 Mai 2004, 135-151, 2004 (in German).

Embleton-Hamann, C.: Austria, in: Geomorphological Hazards of Europe, edited by: Embleton, C. and Embleton-Hamann, C., Elsevier, Amsterdam, 1-30, 1997.

Emerging Health Threats Forum: Culture Sways Views of Disaster Risk, available at: http://anitamakri.com/wp-content/uploads/ 2007/12/EHTF10.08.13_anitamakri.com_.pdf, last access: July 2012, 2008.

European Commission: Communication From the Commission to the European Parliament and the Council, The European Community Response to the Flooding in Austria, Germany and Several Applicant Countries - A Solidarity-Based Initiative, $\operatorname{COM}(2002) 481$ Brussels, Belgium, available at: http://eur-lex. europa.eu/, last access: July 2012, 2002.

European Social Survey: available at: http://www. europeansocialsurvey.org/index.php, last access: August 2012, 2011.

Faber, R.: Flood Risk Analysis: Residual Risks and Uncertainties in an Austrian Context, Unpublished Dissertation, University of Natural Resources and Applied Life Sciences, Vienna, Austria, 2006.

FEMA (Federal Emegrency Management Agency): FEMA's Risk MAP Strategy - Integrating Mapping, Assessment, and Mitigation Planning, available at: http://www.fema.gov, last access: August 2012, 2008.

Fleischhauer, M., Greiving, S., Flex, F., Scheibel, M., Stickler, T., Sereinig, N., Koboltschnig, G., Malvati, P., Vitale, V., Grifoni, P., and Firus, K.: Improving the active involvement of stakeholders and the public in flood risk management - tools of an involvement strategy and case study results from Austria, Germany and Italy, Nat. Hazards Earth Syst. Sci., 12, 2785-2798, doi:10.5194/nhess-12-2785-2012, 2012.

Frei, C., Scholl, R., Fukutome, S., Schmidli, J., and Vidale, P. L.: Future change of precipitation extremes in Europe: Intercomparison of scenarios from regional climate models, J. Geophys. Res., 111, D06105, doi:10.1029/2005JD005965, 2006.

Fuchs, S.: Susceptibility versus resilience to mountain hazards in Austria - paradigms of vulnerability revisited, Nat. Hazards Earth Syst. Sci., 9, 337-352, doi:10.5194/nhess-9-337-2009, 2009.

Ganoulis, J. : An Integrated Approach for Flood Risk Management. Real-Time and Deliberative Decision Making, in: NATO Science for Peace and Security Series C: Environmental Security, edited by: Linkov, I., Ferguson, E., Magar, V. S., Springer, Netherlands, 91-101, 2009.

Gaume, E., Bain, V., Bernardara, P., Newinger, O., Barbuc, M., Bateman, A., Blaškovičová, L., Blöschl, G., Borga, M., Dumitrescu, A., Daliakopoulos, I., and Garcia, J.: A Compilation of Data on European Flash Floods, J. Hydrol., 367, 70-78, 2009.

Gazsó, A.: The Austrian Experience - project NanoTrust, Presentation given at the OECD Working Party on Nanotechnology Workshop on Public Engagement with Nanotechnology, Delft (The Netherlands), 30 and 31 October 2008.

Gierlach, E., Belsher, B. E., and Beutler, L. E.: Cross-Cultural Differences in Risk Perceptions of Disasters, Risk Anal., 30, 15391549, 2010.

Hobfoll, S. E.: The Influence of Culture, Community, and the Nested-Self in the Stress Process: Advancing Conservation of Resources Theory, Appl. Psychol.-Int. Rev., 50, 337-421, 2001.

Homan, J.: A Culturally Sensitive Approach to Risk? "Natural" Hazard Perception in Egypt and the UK, Australian Journal of Emergency Management, 16, 14-18, 2001.

Keiler, M., Knight, J., and Harrison, S.: Climate Change and Geomorphological Hazards in the Eastern European Alps, Philos. T. R. Soc. A, 368, 2461-2479, 2010.

Kosar, B., Gröchenig, S., Leitner, M., Paulus, G., and Ward, S.: The Application of Geospatial Technology in Hazards and Disaster Research: Developing and Evaluating Spatial Recovery Indices to Assess Flood Hazard Zones and Community Resilience in Austrian Communities, edited by: Strobl, J., Blaschke, T., and Griesebner, G., GI-Forum, Herbert Wichmann Verlag, Heidelberg, Germany, 2011. 
Kulmesch, S.: Evaluation of the HAZUS-MH Loss Estimation Methodology for a Natural Risk Management Case Study in Carinthia, Austria. Austrian Marshall Plan Foundation Scholarship Publications, available at: http://www.marshallplan.at, last access: July 2012, 2010.

Nachtnebel, H. P.: Revised Strategies for Flood Risk Management: Lessons from the 2002 Flood in Europe, in: Extreme Hydrological Events: New Concepts for Security, edited by: Vasiliev, O. F., van Gelder, P. H. A. J. M., Plate, E. J., and Bolgov, M. V., Springer, Netherlands, Extreme Hydrological Events: New Concepts for Security NATO Science Series, 78, 417-436, 2007.

Paulus, G., Bäk, R., Flaschberger, G., Gruber, K., Piechl, T., Sereinig, N., and Seymann, C.: Interoperability and Geohazards: A Conceptual Framework for Natural Risk Management in Carinthia, Austria, in: e-Environment: Progress and Challenge, Research on Computing Science, edited by: Prastacos, P., Cortes, U., Diaz de Leon, J. L., and Murillo, M., 11, 219-226, 2004.

Reid, S. G.: Perception and Communication of Risk, and the Importance of Dependability, Struct. Saf., 21, 373-384,1999.

Renn, O.: The Role of Risk Perception for Risk Management, Reliab. Eng. Syst. Safe., 59, 49-62, 1998.

Schmidt, M.: Investigating Risk Perception: A Short Introduction, Chapter 3, in: Loss of Agro-Biodiversity in Vavilov Centers, with a Special Focus on the Risks of Genetically Modified Organisms (GMOs). Unpublished Dissertation. University of Natural Resources and Applied Life Sciences, Vienna, Austria, 2004.

Schönerklee, M.: Advances in Managing Austria's Water Resources, in: Sustainable Use and Development of Watersheds, edited by: Gönenç, İ. E., Vadineanu, A., Wolflin, J. P., and Russo, R. C., NATO Science for Peace and Security Series C: Environmental Security, Springer, Netherlands, 21-49, 2008.
Staffler, H., Pollinger, R., Zischg, A., and Mani, P.: Spatial variability and potential impacts of climate change on flood and debris flow hazard zone mapping and implications for risk management, Nat. Hazards Earth Syst. Sci., 8, 539-558, doi:10.5194/nhess-8539-2008, 2008.

Szabó, J. A.: Decision Supporting Hydrological Model for River Basin Flood Control, in: Digital Terrain Modelling, Peckham, R. J. and Jordan, G., Springer, Berlin Heidelberg, Germany, 145182, 2007.

Thomas, K.: Comparative Risk Perception: How the Public Perceives the Risks and Benefits of Energy Systems, P. Roy. Soc. Lond. A Mat., 376, 35-50, 1981.

UN: Tsunami Recovery Status Report Summary, Document prepared for the United Nations Information Management Service and Reconstruction Agency for Aceh and Nias, 8-58, 2005.

Url, T. and Sinabell, F.: Flood Risk Exposure in Austria - Options for Bearing Risk Efficiently, Journal of applied social science studies, 128, 593-614, 2008.

Ward, S., Leitner, M., and Paulus, G.: Utilizing GIS Technology in Hazards Research: Applying a Spatial Recovery Index to Assess Vulnerability and Community Resilience in Carinthia, Austria, in: Geospatial Crossroads @ GI_Forum '09, edited by: Strobl, J., Blaschke, T., and Griesebner, G., Herbert Wichmann Verlag, Heidelberg, Germany, 2009.

Ward, S., Leitner, M., and Pine, J.: Investigating Recovery Patterns in Post Disaster Urban Settings: Utilizing Geotechnology to Understand Post-Hurricane Katrina Recovery in New Orleans, Louisiana, in: Geospatial Techniques in Urban Hazard and Disaster Analysis, edited by: Showalter, P. S. and Lu, Y., New York, NY: Springer Press, 355-372, 2010.

Zischg, A., Schober, S., Sereinig, N., Rauter, M., Seymann, C., Goldschmidt, F., Bäk, R., and Schleicher, E.: Monitoring the Temporal Development of Natural Hazard Risks as a Basis Indicator for Climate Change Adaptation, Springer, Netherlands, Nat. Hazards, 1-14, doi:10.1007/s11069-011-9927-0, 2011. 